\title{
Spatial Clustering and Temporal Trends in Coronary Heart Disease
}

\author{
An Epidemiological Aid in the Battle against Coronary Heart Disease
}

\author{
Anders Green \\ Department of Epidemiology and Social Medicine, University of Aarhus, Denmark
}

In this issue of Heart Drug, Karvonen et al. [1] report an analysis of the spatial distribution and temporal trends in acute myocardial infarction among men aged 35-74 years in Finland, a country known to feature record high levels of coronary heart disease. The authors have, in a sophisticated way, combined the application of geographical information systems with advanced Bayesian statistical modelling. Geographical mapping of diseases, i.e. cartographic presentation of disease occurrence, is a classical theme in epidemiology, but over the last decade, it has experienced an upsurge thanks to advancements in computing technology [2].

Karvonen et al. [1] demonstrate that whereas the overall incidence of acute myocardial infarction declined considerably in Finland from 1983 to 1993, the skewed spatial distribution of the disease remained roughly constant over the same period. In addition, the authors found that the incidence of acute myocardial infarction was somewhat higher in rural settings as compared with urbanized areas.

The design of the Finnish study raises some questions. It is not clear why only three separate calendar years (1983, 1988 and 1993) were chosen for analysis, considering that in the well-organized Finnish nation - with its long-standing tradition of running national health databases and its unique centralized registration of all inhabitants - it should indeed have been possible to register all events in the study period of 10 years. In addition, to allow for optimal modelling of the incidence rates, such a complete registration would also enable valuable analyses of the spatial distributions of trends in the incidence of myocardial infarction. It also remains unclear why the authors opted to apply a global standard population, dating back more than a decade before the registration period and including a large proportion of subjects younger than those included in the present study, for the provision of age-standardized rates. Why not use a contemporary Finnish standard population, truncated to represent the age span covered by the study? Such a choice would, without changing the statistical inference, most likely produce standardized rates of more immediate relevance for the Finnish population.

What can be learned from the study of Karvonen et al. [1]? The finding of the declining incidence of acute myocardial infarction may very well be interpreted as reflecting an effect of the Finnish coronary heart disease prevention programmes established in the 1970s. In this respect, the study of Karvonen et al. [1] confirms what was already known. To some extent, this also applies to the finding of a skewed spatial distribution that remained virtually unchanged during the study period, with an increasing incidence from south-western to north-eastern Finland. Because the study provides no possible explanations for these findings, the public health implications are

\begin{tabular}{ll}
\hline KARGER & ( ) 2002 S. Karger AG, Basel \\
Fax +4161306 1234 & 1422-9528/02/0022-0049\$18.50/0 \\
$\begin{array}{l}\text { E-Mail karger@karger.ch } \\
\text { www.karger.com }\end{array}$ & $\begin{array}{l}\text { Accessible online at: } \\
\text { www.karger.com/journals/hed }\end{array}$
\end{tabular}

Prof. Anders Green, MD, PhD, Dr Med Sci

Department of Epidemiology and Social Medicine, University of Aarhus

Vennelyst Boulevard 6

DK-8000 Århus C (Denmark)

Tel. +458942 6097, Fax +458942 6197, E-Mail ag@soci.au.dk 
less obvious. Nevertheless, the public health relevance may be more evident from further developments of the methods of analysis presented by Karvonen et al. [1], for example, by the incorporation of population indicators of the levels of relevant risk factors (like blood pressure, cholesterol, smoking habits, body mass index and physical activity). If such information was available from health databases, risk indicators could be incorporated together with the registration of new cases of disease within the same geographical units ('grids').

The importance of the study of Karvonen et al. [1] lies most of all in the demonstration of the potential usefulness of sophisticated computer-assisted methods of statistical-epidemiological analysis applied to a major public health problem like coronary heart disease. This is fascinating, yet somewhat frustrating when seen in a broader perspective. For years it has been possible, via satellites and other instruments, to collect data that permit us to monitor, for example, the climate worldwide as well as in extreme detail at the regional level. Thus, we know much more about the global and regional climate and its changes than we know about the geographical distribution (prevalence) and dynamics (incidence and patient mortality) of most diseases of major public health concern. Pioneering activities like the publication of cancer atlases [3], a European atlas of avoidable deaths [4] and, more recently, a global diabetes atlas [5] not only illustrate the attempts to produce such scientifically based global information, but also testify to the problems in doing so because of limited availability of the empirical data needed.
The continuous monitoring of the spatial distribution and temporal trends of the major chronic diseases is of essential importance, because this kind of information is vital for generating hypotheses concerning the aetiology and natural history of these diseases, in which multiple determinants, including genetic, environmental and behavioural factors, are assumed to operate in a complex manner. Furthermore, information from epidemiological monitoring provides an important reference for the assessment of possible effects of intervention programmes and improved treatment modalities. At the regional level, epidemiological monitoring requires reliable information on the demographic size, composition and temporal changes of the population at risk. Also required is access to valid and comprehensive disease registration systems that provide information on new cases of disease and deaths and migrations among already registered patients. The classical disease registers will most likely be replaced gradually by regional, and maybe even national, clinical databases, which are being established in increasing numbers. When further developed and tested, the methodology used by Karvonen et al. [1] may very well become an integral part of the utilization of data contained in disease registers and clinical databases for the purpose of routine epidemiological monitoring of the spatial distribution and temporal trends of the major chronic diseases. In this respect, the Finnish study confirms why it is so important to apply modern statistical-epidemiological methods to basic patient data used in clinical practice in the fight against major public health problems like coronary heart disease.

\section{References}

1 Karvonen M, Moltchanova E, Viik-Kajander M, Moltchanov V, Rytkönen M, Kousa A, Tuomilehto J: Regional inequality in the risk of acute myocardial infarction in Finland: A case study of 35- to 74-year-old men. Heart Drug 2002;2:51-60.

2 Bernardinelli L, Clayton D, Pascutto C, Montomoli C, Ghislandi M, Songini M: Bayesian analysis of space-time variation in disease risk. Stat Med 1995;14:2433-2444.
3 Ferlay J, Bray F, Pisani P, Parkin DM: GLOBOCAN 2000: Cancer Incidence, Mortality and Prevalence Worldwide, Version 1.0. IARC CancerBase No. 5. Lyon, IARC, 2001.

4 Holland WW (ed): European Community Atlas of Avoidable Deaths. Oxford, Oxford University Press, 1988.

5 Allgot B, Gan D, Alberti KGMM, Aschner P, Bonnici F, Jervell J, Leuner S, Mahtab FU, Murphy M, Murray S, Rafique G, Taylor C, Chuan TA, Vinicor F, Williams R, Zimmet P (eds): Diabetes Atlas 2000. Brussels, The International Diabetes Federation, 2000. 